\title{
Baclofen Abuse due to Its Hypomanic Effect in Patients with Alcohol Dependence and Comorbid Major Depressive Disorder
}

\author{
Soumitra Ghosh, Dhrubajyoti Bhuyan \\ Department of Psychiatry, Assam Medical College and Hospital, Dibrugarh, Assam, India
}

Baclofen is a gamma-aminobutyric acid type B receptor agonist used as an anti-craving agent for treatment of alcohol dependence. It has gained popularity in the recent times because it is well tolerated even in patients with hepatic impairments. Herein we are summarizing the latest literature about baclofen induced hypomania and are reporting a case of baclofen abuse because of its mood elevating property in a patient of alcohol dependence with comorbid major depressive disorder. Literature review and case study of a 36-year-old male with alcohol dependence with comorbid major depressive disorder was prescribed with tablet baclofen as an anti-craving agent along with antidepressant medicines. The patients who did not improve with conventional antidepressant therapy started feeling better in terms of his mood symptoms on taking tablet baclofen. Owing to the mood elevating property he started abusing baclofen. Despite its safety profile in hepatic impairment, one must be very cautious in prescribing baclofen because of its mood altering property which may account for its abuse potentiality.

KEY WORDS: Baclofen; Alcoholism; Treatment-resistant depressive disorder; Baclofen abuse.

\section{INTRODUCTION}

Baclofen is a gamma-aminobutyric acid type $\mathrm{B}(\mathrm{GABA}-\mathrm{B})$ receptor agonist used primarily in the treatment of spasticity and in recent years it has gained popularity as an anti-craving medicine for the treatment of alcohol dependence syndrome. $^{1,2)}$

The anti-craving and anti-reward effects of baclofen are attributed to its agonist effect on GABA-B receptors in the ventral tegmental area, which are reported to control the activity of mesolimbic dopamine neurons, one of the major pathways in the regulation of the reinforcing properties of drugs of addiction. ${ }^{3,4)}$

Baclofen is found to be effective and well tolerated by patients with hepatic impairment also. A provisional evidence of dose-response effect has been demosntarted by Addolorato et al. ${ }^{5)}$ with $20 \mathrm{mg}$ three times a day (TDS) dose found to be more effective than $10 \mathrm{mg}$ TDS in suppression of carving for alcohol. There have been individual case reports of using baclofen in a much higher

\footnotetext{
Received: March 18, 2016 / Revised: May 18, 2016

Accepted: May 19, 2016

Address for correspondence: Dhrubajyoti Bhuyan, MD

Department of Psychiatry, Assam Medical College and Hospital, Dibrugarh, Assam 786002, India

Tel: +91-9435030212, Fax: +91-373-2302952

E-mail: dr.dhrubajyoti@gmail.com
}

dose, i.e. $270 \mathrm{mg}$ /day for suppressing the craving for alcohol. However there is no systematic study on the use of higher doses. ${ }^{6,7)}$

However recently published case reports have shown several serious safety concerns which includes drowsiness, seizure vulnerability, risk for triggering specific pharmacologic withdrawal syndrome and intoxication. ${ }^{8-11)}$

Baclofen has previously been reported for inducing behavioural disinhibition and manic like symptoms. ${ }^{1,2)}$ Due to its mood elevating property its abuse potentiality cannot be ruled out.

Here we are presenting a case of baclofen abuse in a patient with alcohol dependence with comorbid major depressive disorder who reported to have used baclofen in order to overcome his depression.

\section{CASE}

A 36 years old Hindu, literate married male patient from urban background took treatment for alcohol dependence and recovered well. He was prescribed with baclofen 30 mg daily. He was better but often on, he used to drink alcohol along with his medication baclofen. On enquiry he was found to be having moderate depression with sleep problem for last 1 year. He was prescribed with mirtazepine $15 \mathrm{mg}$ daily at bedtime and lorazepam $2 \mathrm{mg}$. He con-

(a) This is an Open-Access article distributed under the terms of the Creative Commons Attribution Non-Commercial License (http://creativecommons.org/licenses/by-nc/4.0) which permits unrestricted non-commercial use, distribution, and reproduction in any medium, provided the original work is properly cited. 
Table 1. The Naranjo adverse drug reaction probability scale and its responses

\begin{tabular}{|c|c|c|c|c|}
\hline $\begin{array}{l}\text { The Naranjo adverse drug reaction probability scale; To assess the adverse drug reaction, } \\
\text { please answer the following questionnaire and give the pertinent score }\end{array}$ & Yes & No & $\begin{array}{l}\text { Do not } \\
\text { know }\end{array}$ & Score \\
\hline 1. Are there previous conclusive reports on this reaction? & +1 & 0 & 0 & +1 \\
\hline 2. Did the adverse event occur after the suspected drug was administered? & +2 & -1 & 0 & +2 \\
\hline 3. Did the adverse reaction improve when the drug was discontinued or a specific antagonist was administered? & +1 & 0 & 0 & +1 \\
\hline 4. Did the adverse reaction reappear when the drug was re-administered? & +2 & -1 & 0 & +2 \\
\hline 5. Are there alternative causes (other than the drug) that could have on their own caused the reaction? & -1 & +2 & 0 & -1 \\
\hline 6. Did the reaction reappear when a placebo was given? & -1 & +1 & 0 & 0 \\
\hline 7. Was the blood detected in the blood (or other fluids) in concentrations known to be toxic? & +1 & 0 & 0 & 0 \\
\hline 8. Was the reaction more severe when the dose was increased or less severe when the dose was decreased? & +1 & 0 & 0 & +1 \\
\hline 9. Did the patient have a similar reaction to the same or similar drugs in any previous exposure? & +1 & 0 & 0 & +1 \\
\hline 10. Was the adverse event confirmed by any objective evidence? & +1 & 0 & 0 & 0 \\
\hline Total & & & & 7 \\
\hline
\end{tabular}

The adverse drug reaction is assigned to a probability category from the total score as follows: definite if the overall score is 9 or greater, probable for a score of $5-8$, possible for $1-4$ and doubtful if the score is $0 .{ }^{15}$ )

tinued for two months but there was no significant improvement. Therefore he was prescribed with escitalopram $20 \mathrm{mg}$ daily along with the previous medication. He was continuing for months but still there was no improvement. He was always complaining of sleep problem in spite of all those medications. So he was prescribed with quetiapine $100 \mathrm{mg}$ daily along with mirtazepine 15 $\mathrm{mg}$, escitalopram $20 \mathrm{mg}$, lorazepam $2 \mathrm{mg}$, and baclofen 20 $\mathrm{mg}$ daily. Patient remained sober and off alcohol. He was continuing all those medication without much improvement of his depression. So he discontinued coming for checkup. On the next visit when he came after seven months he revealed that he was only taking mirtazepine 15 $\mathrm{mg}$, lorazepam $2 \mathrm{mg}$ and whenever he takes baclofen 80 mg daily along with those medication he feels much better. His family member also gave history that whenever he takes baclofen $80 \mathrm{mg}$ and sometimes more than that dose his confidence increases becomes irritable and angry. He remains euphoric and sleeps less; remain restless most of the time. But his work function remains same without deterioration. On understanding his change of behavior after abusing baclofen $80 \mathrm{mg}$ they stopped baclofen but immediately the patient becomes depressed like before. It means the patient was having hypomanic switch on taking $80 \mathrm{mg}$ of baclofen. Interestingly during his hypomanic phase he never took alcohol which is most probably for taking baclofen which is an anti-craving drug for alcohol.

\section{DISCUSSION}

There have been many case reports depicting manic or hypomanic episode resulting from use of baclofen. ${ }^{1,2)}$ The mood elevating property of baclofen has not been properly known. However it is postulated that mood altering property of baclofen may be due to its GABA-B receptor agonist action which results - (a) acceleration of noradrenaline turnover by changing post synaptic receptor density and (b) up regulation of serotonin $\left(5 \mathrm{HT}_{2}\right)$ receptor thereby leading to diminished liberation of serotonin. ${ }^{12)}$

To our knowledge, abusing baclofen due to it mood elevating property has not been reported till date in literature. Herein we are reporting such a case. Our patient who did not show any improvement on antidepressant medicines reported to have felt better in terms of his mood state whenever he takes baclofen. The patient may be regarded as a case of resistant depression as per the criteria. He reported that whenever he takes higher doses of baclofen his confidence increases becomes irritable and angry. This indicates that mood elevating property of baclofen is dose dependant. Hypomania/mania symptom checklist (HCL-32) by Angst et al. ${ }^{13)}$ was applied and the score was found to be 12. Naranjo algorithm ${ }^{14)}$ was also applied to ascertain the occurrence of such hypomanic symptoms in the patients and the results are shown in Table $1 .{ }^{15)}$

In our case the score was 7 which means hypomania is probably related to baclofen use and because of it he has started abusing baclofen.

Baclofen has in recent time gained popularity as an anti-craving agent due to its safety profile in hepatic compromised patients. However, one must be very cautious in using it because of its abuse potential due to its mood elevating property. One possible positive outcome of this report may be that it may be a potential area of research to find out whether baclofen can be used in the treatment of resistant depression.

\section{REFERENCES}

1. Geoffroy PA, Auffret M, Deheul S, Bordet R, Cottencin O, 
Rolland B. Baclofen-induced manic symptoms: case report and systematic review. Psychosomatics 2014;55:326-332.

2. Silva JV, Pinheiro J, Mota J. Baclofen-induced manic episode - a case report. IJCNMH 2015;(2 Suppl 1):P59.

3. Addolorato G, Caputo F, Capristo E, Domenicali M, Bernardi M, Janiri L, et al. Baclofen efficacy in reducing alcohol craving and intake: a preliminary double-blind randomized controlled study. Alcohol Alcohol 2002;37:504508.

4. Colombo G, Addolorato G, Agabio R, Carai MA, Pibiri F, Serra $\mathrm{S}$, et al. Role of $G A B A(B)$ receptor in alcohol dependence: reducing effect of baclofen on alcohol intake and alcohol motivational properties in rats and amelioration of alcohol withdrawal syndrome and alcohol craving in human alcoholics. Neurotox Res 2004;6:403-414.

5. Addolorato G, Leggio L, Ferrulli A, Cardone S, Bedogni G, Caputo F, et al; Baclofen Study Group. Dose-response effect of baclofen in reducing daily alcohol intake in alcohol dependence: secondary analysis of a randomized, doubleblind, placebo-controlled trial. Alcohol Alcohol 2011;46: 312-317.

6. Ameisen O. Complete and prolonged suppression of symptoms and consequences of alcohol-dependence using highdose baclofen: a self-case report of a physician. Alcohol Alcohol 2005;40:147-150.

7. Bucknam W. Suppression of symptoms of alcohol dependence and craving using high-dose baclofen. Alcohol Alcohol 2007; 42:158-160.
8. Franchitto N, Pelissier F, Lauque D, Simon N, Lançon C. Self-intoxication with baclofen in alcohol-dependent patients with co-existing psychiatric illness: an emergency department case series. Alcohol Alcohol 2014;49:79-83.

9. Pommier P, Debaty G, Bartoli M, Viglino D, Carpentier F, Danel V, et al. Severity of deliberate acute baclofen poisoning: a nonconcurrent cohort study. Basic Clin Pharmacol Toxicol 2014;114:360-364.

10. Lee TH, Chen SS, Su SL, Yang SS. Baclofen intoxication: report of four cases and review of the literature. Clin Neuropharmacol 1992;15:56-62.

11. Rolland B, Jaillette E, Carton L, Bence C, Deheul S, Saulnier F, et al. Assessing alcohol versus baclofen withdrawal syndrome in patients treated with baclofen for alcohol use disorder. J Clin Psychopharmacol 2014;34:153156.

12. Bartholini G. GABA receptor agonists: pharmacological spectrum and therapeutic actions. Med Res Rev 1985;5:5575.

13. Angst J, Adolfsson R, Benazzi F, Gamma A, Hantouche E, Meyer TD, et al. The HCL-32: towards a self-assessment tool for hypomanic symptoms in outpatients. J Affect Disord 2005;88:217-233.

14. Naranjo CA, Busto U, Sellers EM, Sandor P, Ruiz I, Roberts EA, et al. A method for estimating the probability of adverse drug reactions. Clin Pharmacol Ther 1981;30:239-245.

15. Zaki SA. Adverse drug reaction and causality assessment scales. Lung India 2011;28:152-153. 